\title{
Effect of Stress Management Training with Cognitive-Behavioral Therapy on Marital Adjustment in the Wives of War Veterans Suffering from Post-Traumatic Stress Disorder
}

\author{
Seyed Abolghasem Mehrinejad ${ }^{1 *}$, Marziye Mokarrami², Zohre Ostovar ${ }^{2}$ \\ ${ }^{1}$ Department of Psychology, Faculty of Psychology and Education, Alzahra University, Tehran, Iran \\ ${ }^{2}$ Department of Psychology, Islamic Azad University of Alborz, Karaj, Iran
}

\section{A BSTRACT}

Introduction: The aim of this study was to investigate the efficacy of cognitive behavioral stress management training on marital adjustment in the wives of the war veterans suffering from posttraumatic stress disorder (PTSD). PTSD is known as a stressful issue in veterans' wives; thus, it can decrease their dyadic adjustment. Materials and Methods: Experimental group included 12 wives who were selected among 30 after training and 12 wives were selected randomly as a control group. Training program included ten 90-minute sessions. The dyadic adjustment questionnaire was Spanier. Results: The results showed that there were significant differences between experimental pretest, posttest, and follow up data in experimental group. Furthermore, significant differences were observed between posttest follow up results in experimental and control groups but there were no significant difference in pretest scores. Conclusion: Marital adjustment can be enhanced by cognitive behavioral stress management training in the wives of the war veterans suffering from PTSD.

* Corresponding Author: Seyed Abolghasem Mehrinejad

\section{Key words:}

1. Education

2. Veterans

3. Stress Disorders, Post-Traumatic

E-mail:ab_mehrinejad@yahoo.com 
اثر آموزش مديريت استرس به شيوه درمان شناختى -رفتارى بر سازخارى زناشويى در همسران

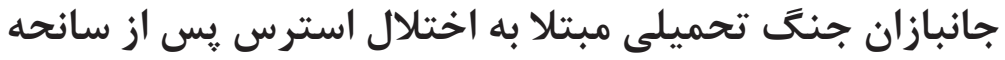

\author{
سيد ابوالقاسم مهرى نزاد"'، مرضيه مكر مى'، زهره استوار؟ \\ 'كروه روانشناسى، دانشكده علوم تربيتى و روانشناسى، دانشكاه الزهرا (س)، تهران، ايران

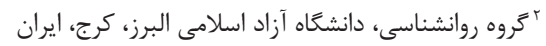

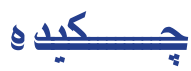

مقدمه: هدف از اين مطالعه، بررسى اثر آموزش مديريت استرس شناختى -رفتارى بر ساز كارى زناشويى إنى إنس

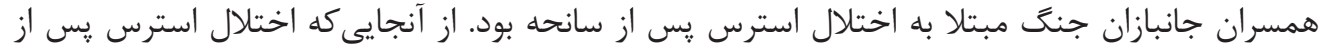

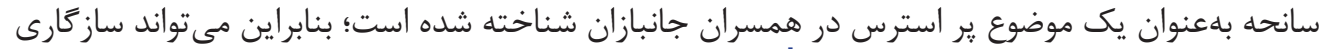

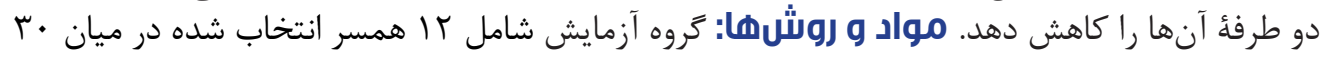

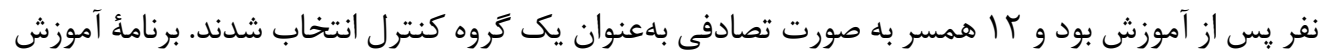

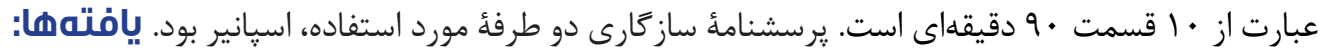

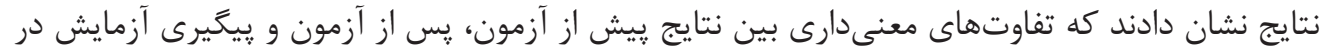

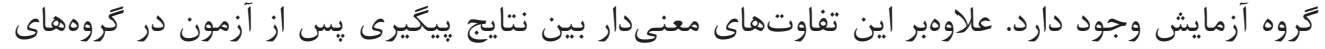

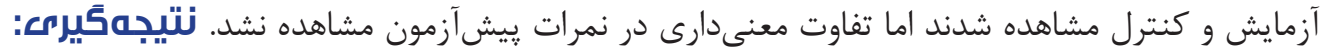

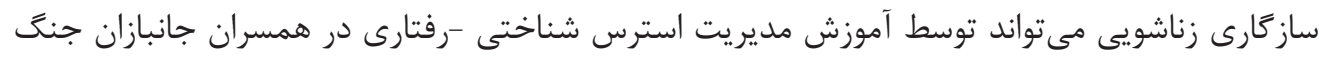
مبتلا به اختلال استرس يس إن از سانحه افزايش يابد.

كليد وازهها:

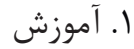

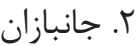

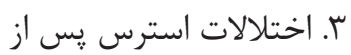

سانحه

" نويسنده مسئول: سيد ابوالقاسم مهرى نزاد آدرس الكترونيكى: 
استرسزاى ويزه براى خانواده است. بر اثر بيمارى بيوندهاى

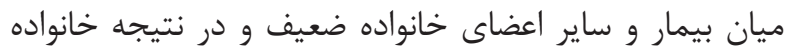

دجار نوعى بحران مىشود (9).

فقدان مهارت در حل تعارض و در نتيجه ناسازكارى زناشويى،

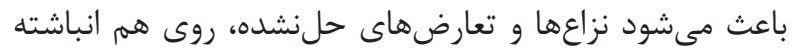

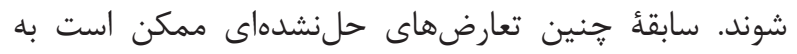

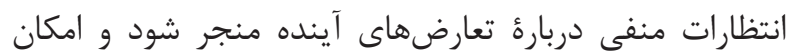

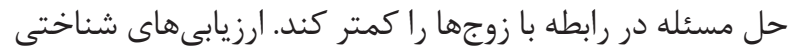

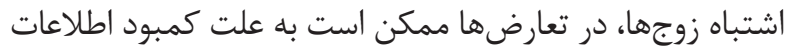

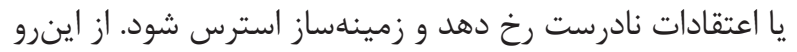

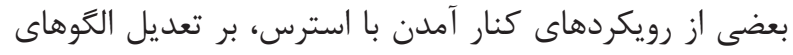

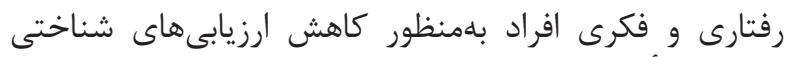

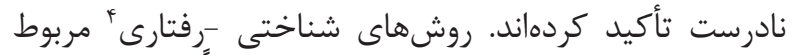

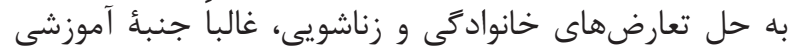

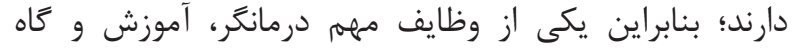

مدلسازى مهارتهاى جديد است (V) مارني

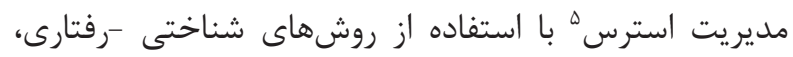

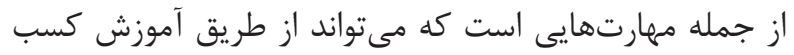

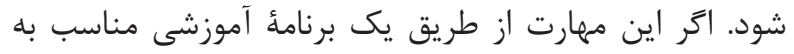

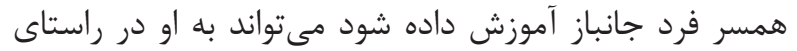

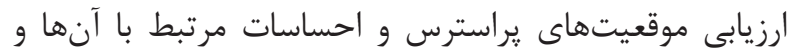

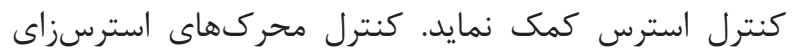

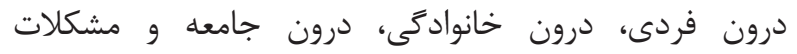

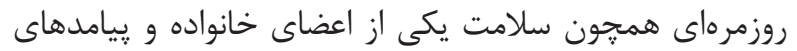

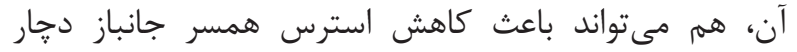

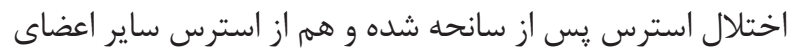

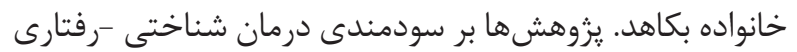

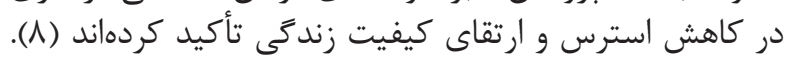

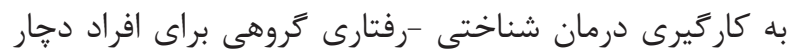

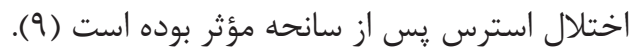

برخى از يزوهش ها به استرس همسر فرد مبتلا به اختلال استرس

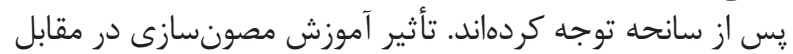

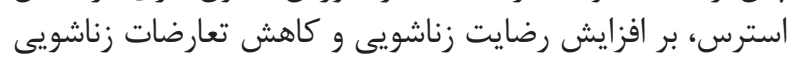

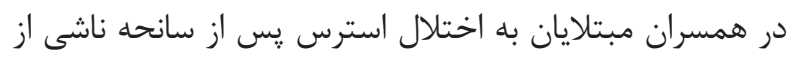

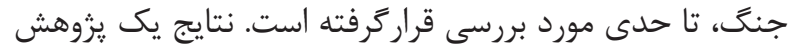

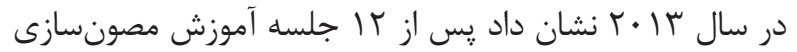

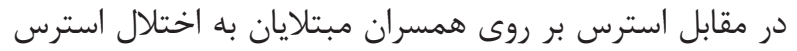

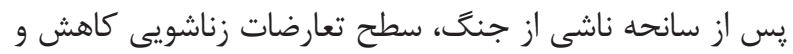

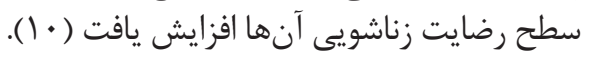

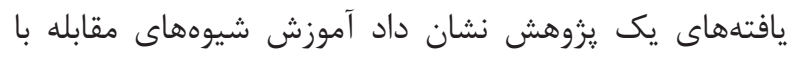

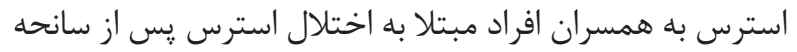

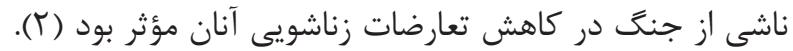

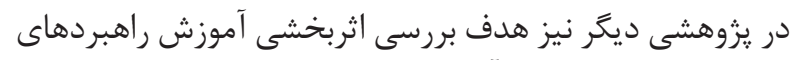

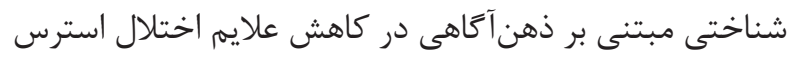

${ }^{1}$ Posttraumatic stress disorder

${ }^{2}$ Marital conflicts

${ }^{3}$ Skill
مقدمه

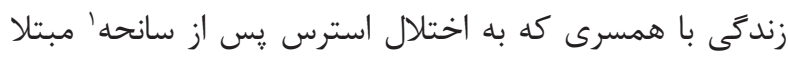

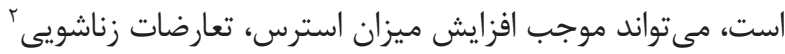

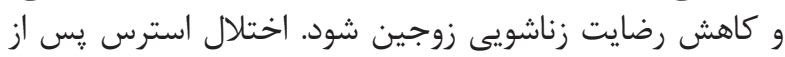

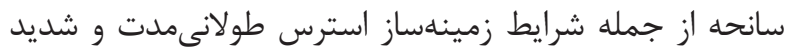

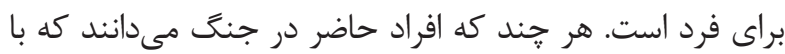

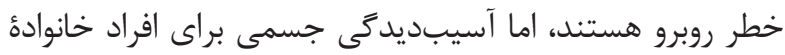

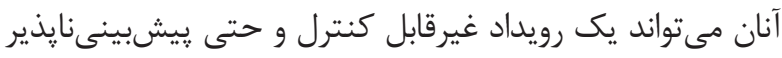

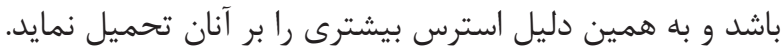

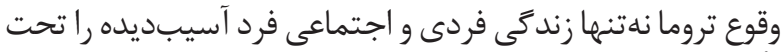

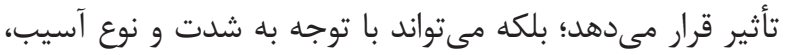

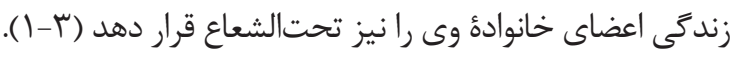

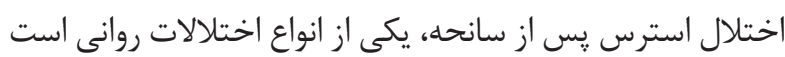

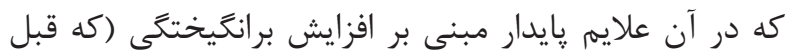

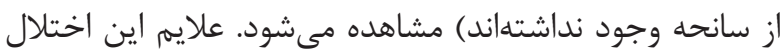

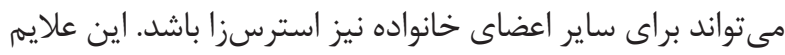

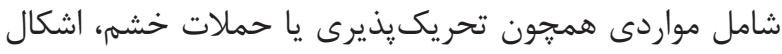

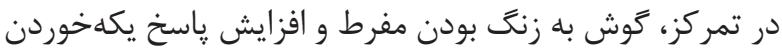

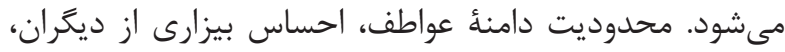

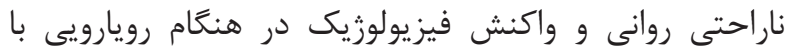

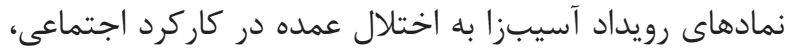

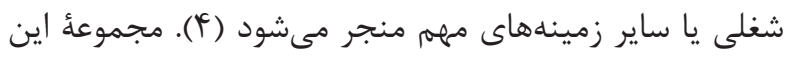

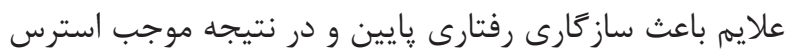

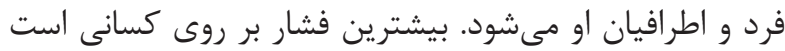

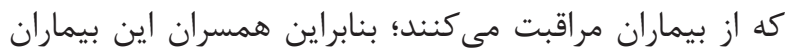

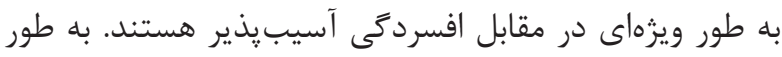

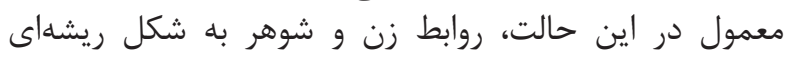

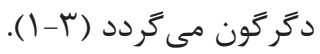

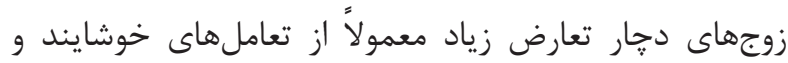

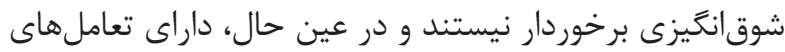

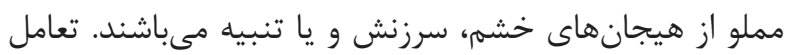

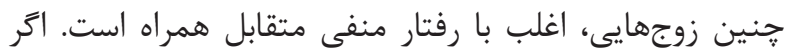

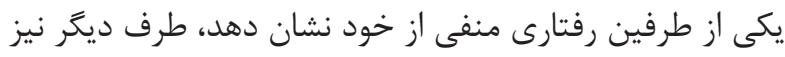

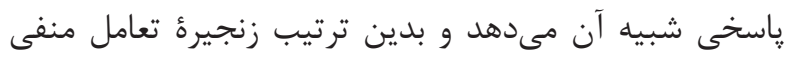

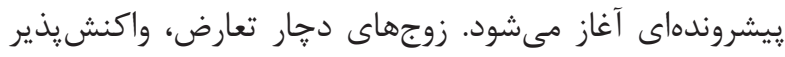

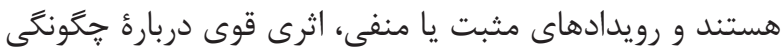
احساس آنها از ارتباط و ارزيابى آن ارتباط در هر هر زمان دمارئ معينى

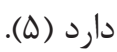

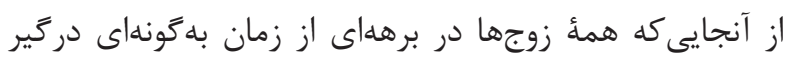

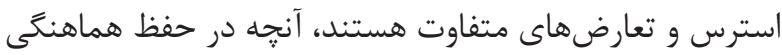

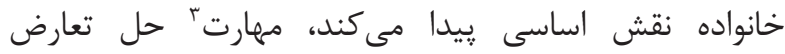

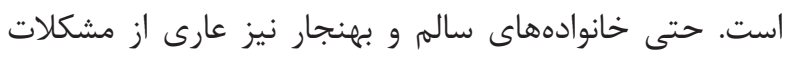

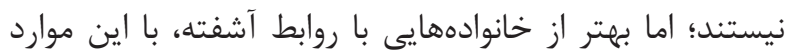

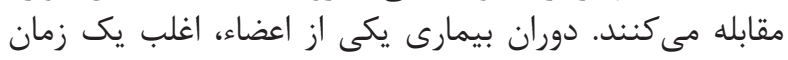

\footnotetext{
${ }^{4}$ Cognitive- behavior techniques

${ }^{5}$ Stress management
} 
با همسران جانبازان دجار اختلال استرس پِ يس از سانحة شهر

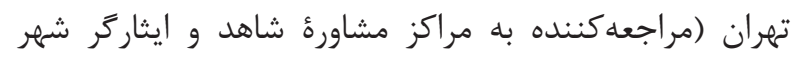

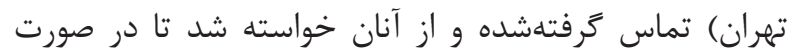

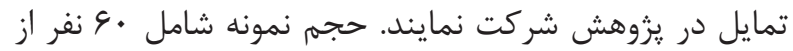

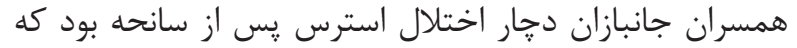

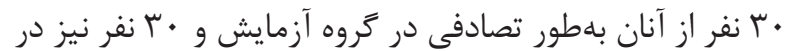
كروه كنترل قرار كرفتند.

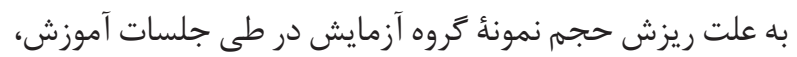

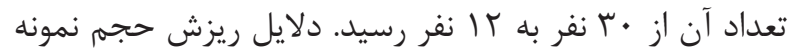

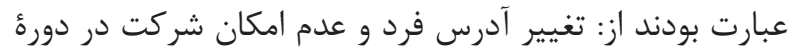

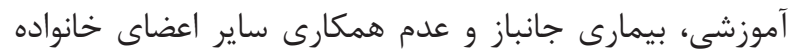

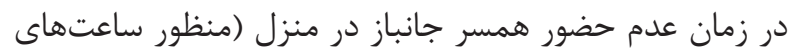

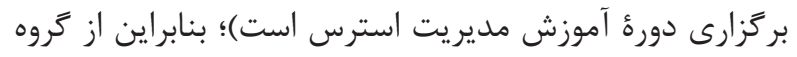

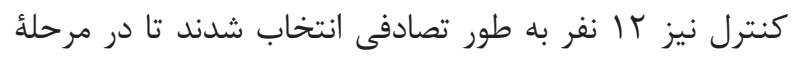

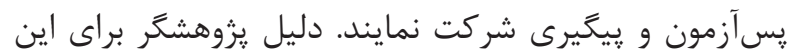

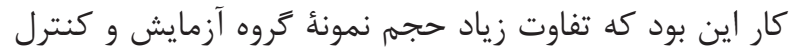

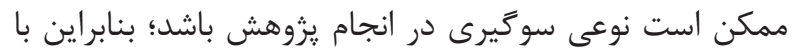

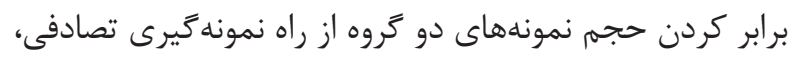

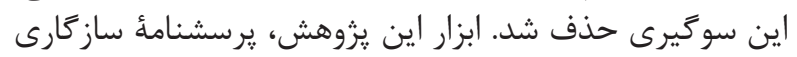

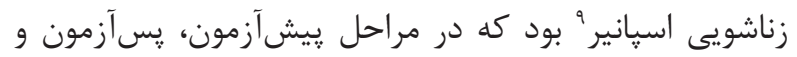

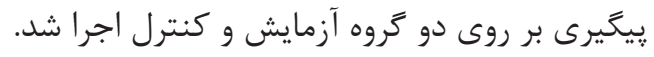

\section{يرسشنامة سازكارى زناشويى اسيانير}

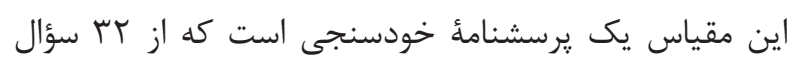

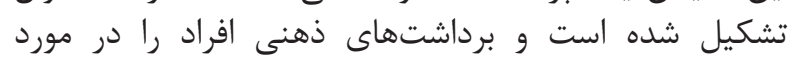

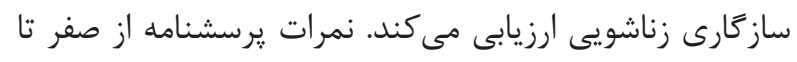

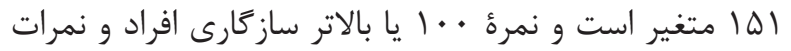

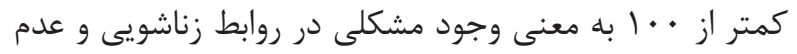

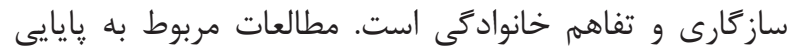

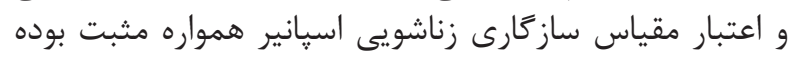

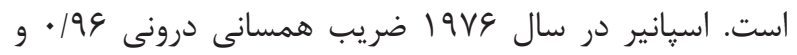

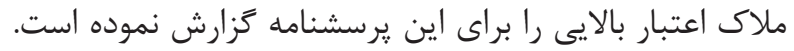

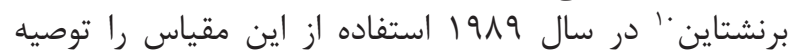

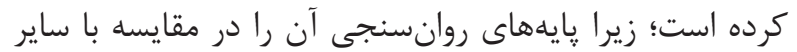

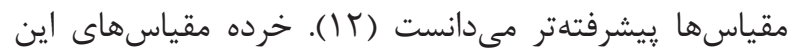

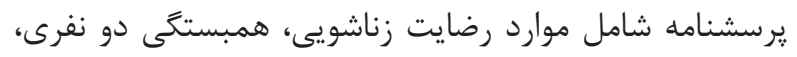

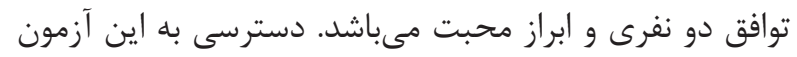

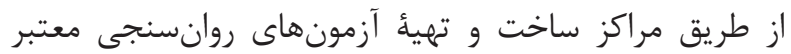
ممكن (http://www.azmonyar.com/Contact_List.aspx)

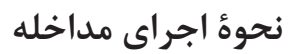

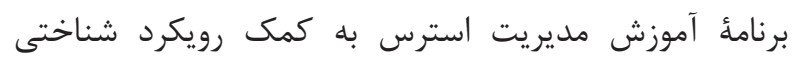

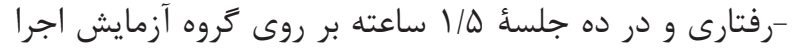

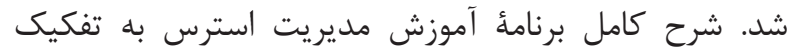

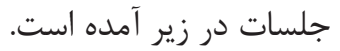

\footnotetext{
${ }^{6}$ Depression

${ }^{7}$ Attitude

${ }^{8}$ Negative automatic thoughts
}

و مشكلات روانشناختى همسران افراد دجار اختلال استرس

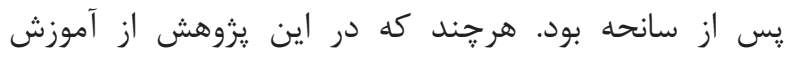

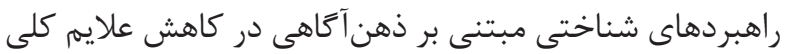

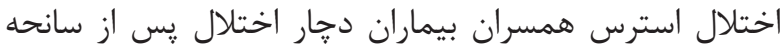

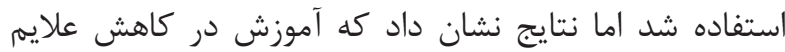

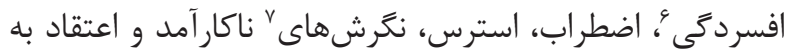

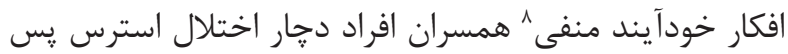

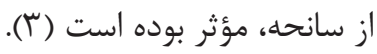

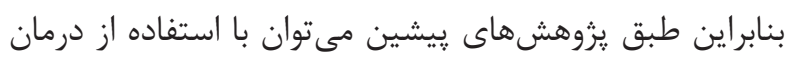

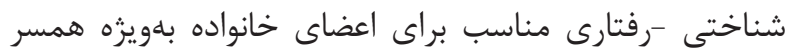

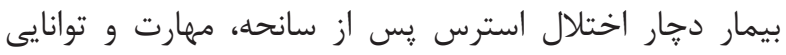

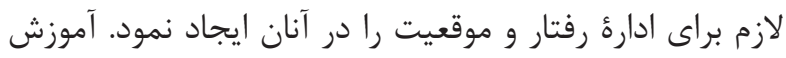

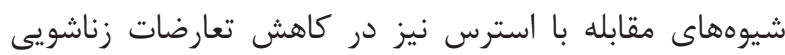

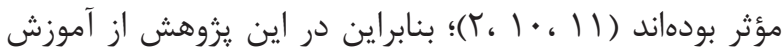

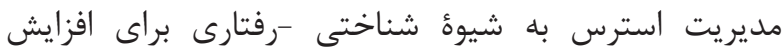

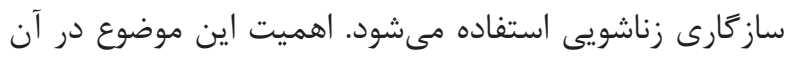

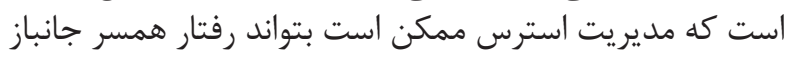

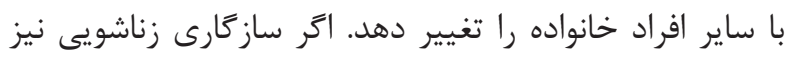

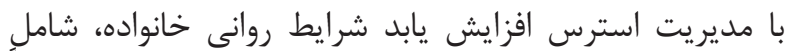

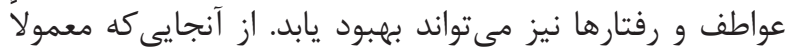

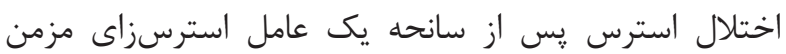

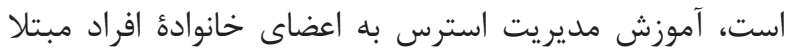

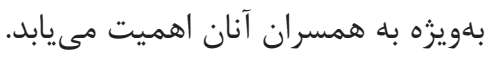

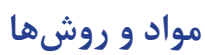

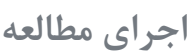

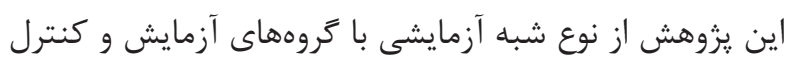

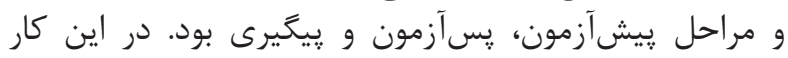

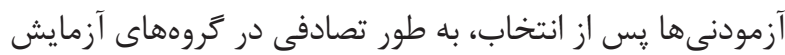

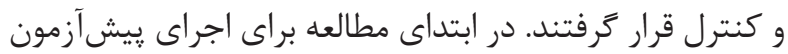

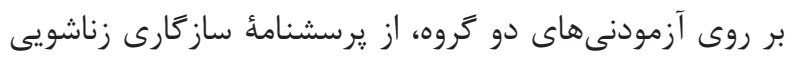

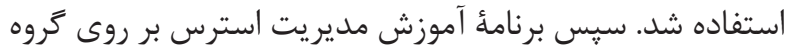

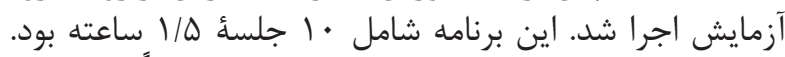

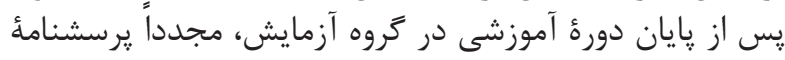

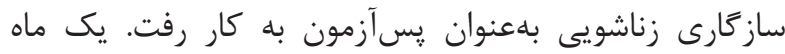

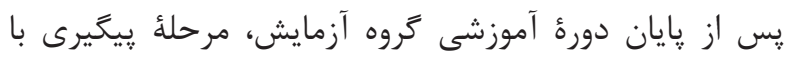

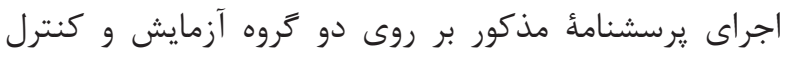

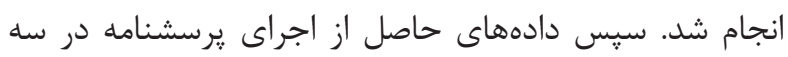

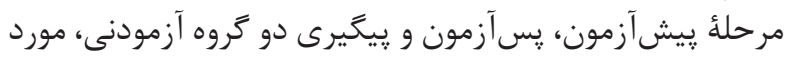

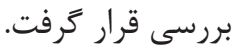

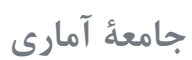

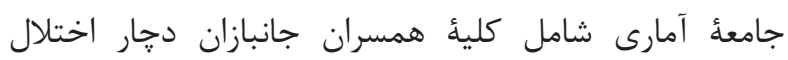

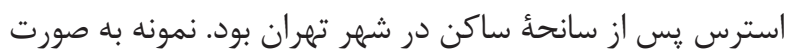

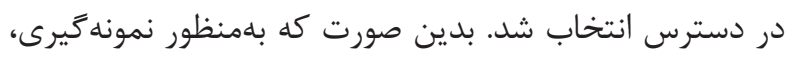

${ }^{9}$ Dyadic adjustment scale, Spanier

${ }^{10}$ Bernstein 
خانكى و بيشنهادهاى عملى به اعضاء داده شد.

جلسةٔ هشتم: ضمن جمعبندى آموزشهاى جلسات قبل و

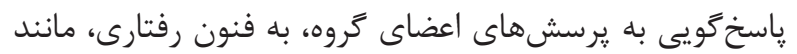

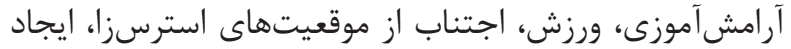

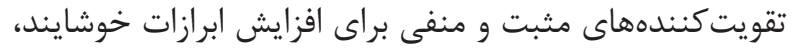

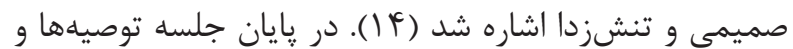
تكاليف عملى ارائه گرديد.

جلسةٔ نهم: آموزشهاى قبلى تكميل و تكاليف خانكى مربوط

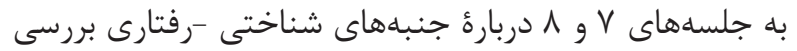

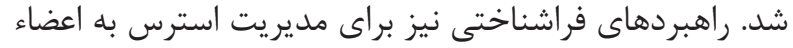
آموزش داده شد (4 أ ، 11).

جلسةٔ دهم: آموزشهاى 9 جلسئ قبل مرور و به مشكلات

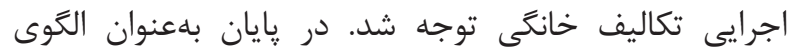

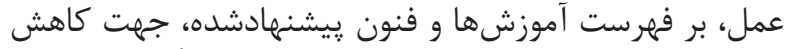

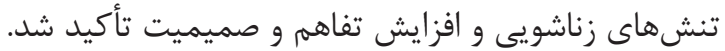

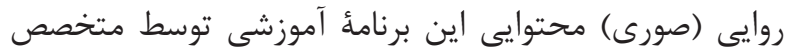

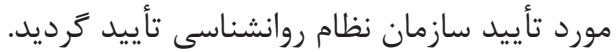

$$
\text { تجزيه و تحليل آمارى }
$$

در بررسى يافتههاى يزوهش از نرمافزار آمارى SPSS" إسى دئفاده

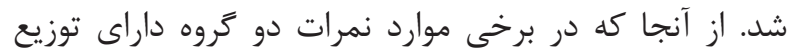

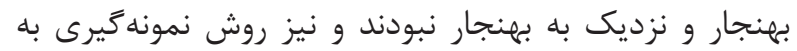

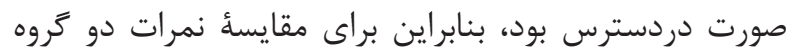

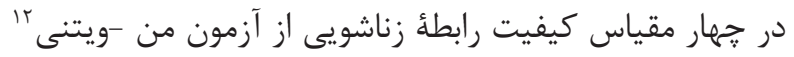

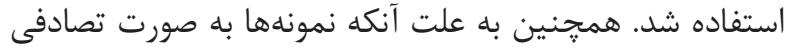

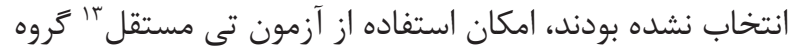

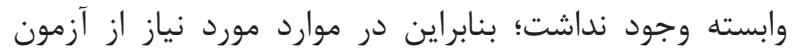

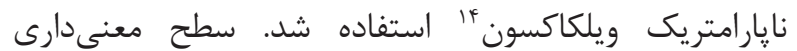

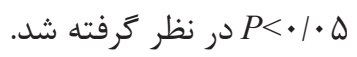

بافته ها

اعضاى نمونه داراى تحصيلات دييلم، در سطح اقتصادى متوسط،

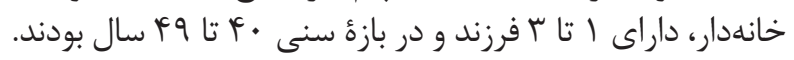

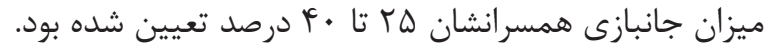

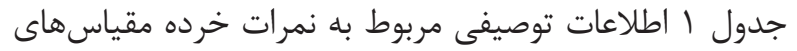

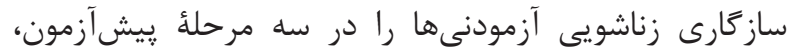

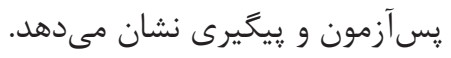

يس از آنكه بررسىها نشان داد مقايسةُ نمرات دو گروه آزمايش

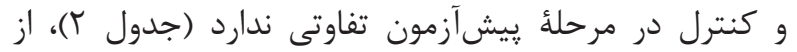

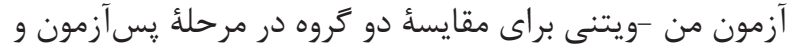
سيس קِيخيرى استفاده شد.

همان گونه كه در جدول ب نشان داده شده است، در مرحلة يسآزمون بين نمرات كليئ خرده مقياسهان

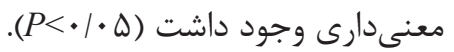

${ }^{11}$ Statistical package for the social sciences

${ }^{12}$ Mann-Whitney U Test

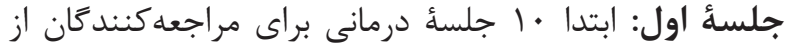

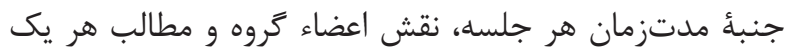

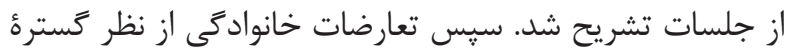

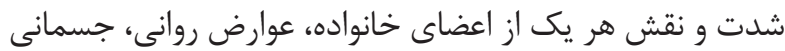

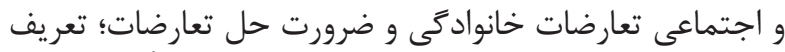

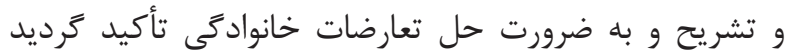

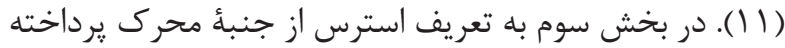

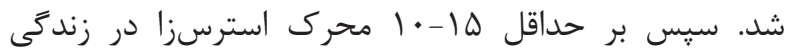

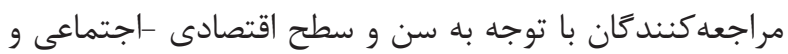

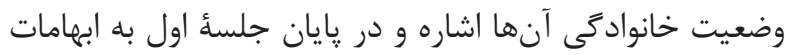

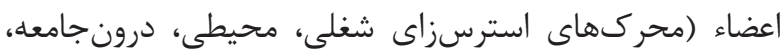

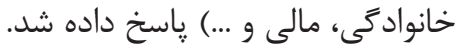
جلسةٔ دوم: ه دقيقة اول به يادآورى فهرستوار مطالب

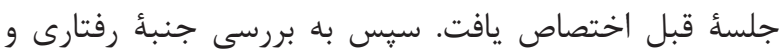
فيزيولوزيك استرس اشاره كرديد (باصن (1).

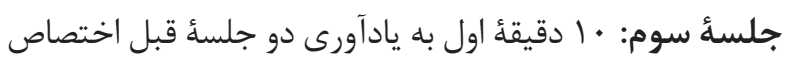

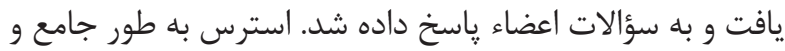

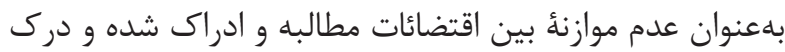

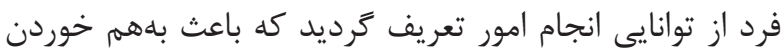

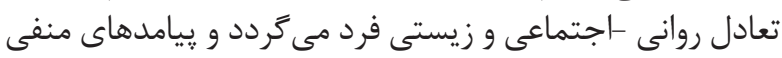

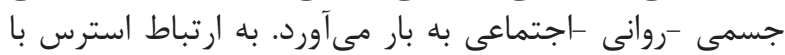

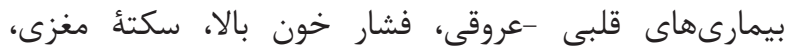

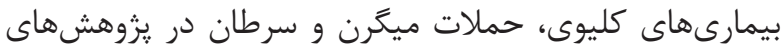

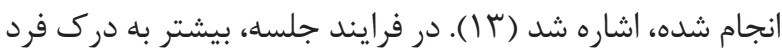

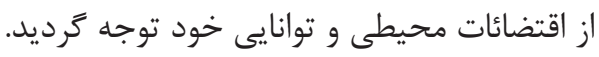

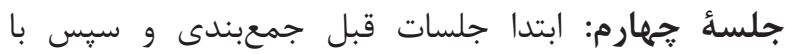

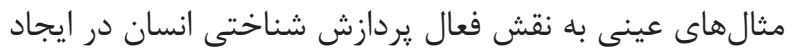

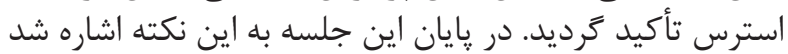

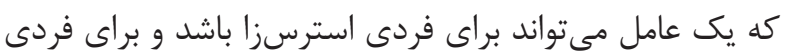

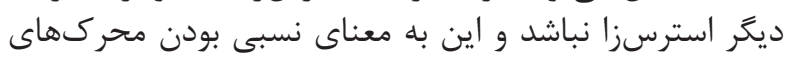

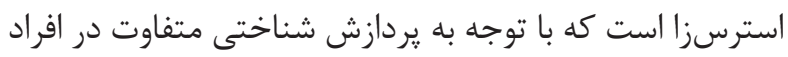
رخ مىدهد. در يايان جلسه، تكليف خانكى به اعضه اعضاء ارائه شد.

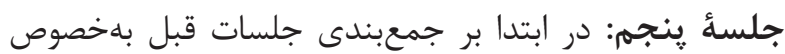

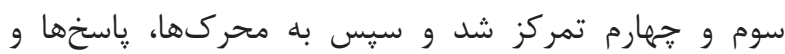

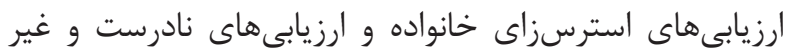

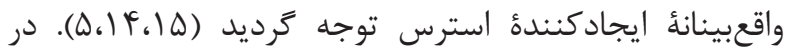
يايان بيشنهادهاى عملى ارائه خرديد.

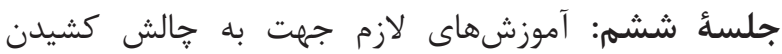

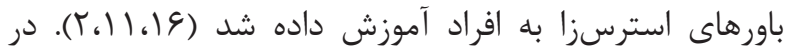

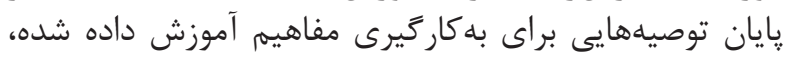

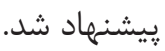

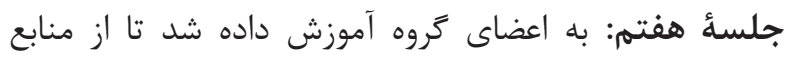

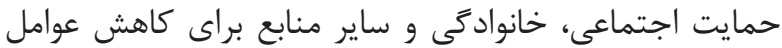

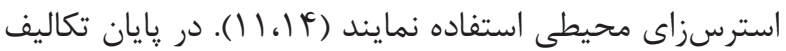

\footnotetext{
${ }^{13}$ Independent samples t- test

${ }^{14}$ Wilcoxon signed-rank test
} 


\begin{tabular}{|c|c|c|c|c|}
\hline اثحراف استاندارث & ميانكين & تعداد & مرحله & متغير \\
\hline Q/TT & $r \cdot / r \wedge$ & TY & ييشآزمون & \multirow{3}{*}{ رضايت زناشـوبـى } \\
\hline $1 / 90$ & TtKO & tF & يسىآزمون & \\
\hline N/T & rq/r^ & tr & ييگيرى & \\
\hline V/ft & $11 / \cdot 1$ & rk & ييشآزمون & \multirow{3}{*}{ همبستخَى دو نفرى } \\
\hline$N / F D$ & $10 / 4 \wedge$ & TF & يسىآزمون & \\
\hline \&IAD & IT/AK & tY & ييغيرى & \\
\hline$M T / I F$ & TA/TL & TY & ي يِشآزمون & \multirow{3}{*}{ توافق دو نفرى } \\
\hline $9 / 41$ & rTIV & TF & يسىآزمون & \\
\hline$\Delta / \Delta \Lambda$ & rq/०० & TH & ييخيرى & \\
\hline T/OV & $F / I V$ & tF & ي بيش آزمون & \multirow{3}{*}{ ابراز محبت } \\
\hline$r / \cdot V$ & GIGT & tr & يسىآزمون & \\
\hline ث & $9 / 9 \mathrm{~V}$ & rF & ييحيرى & \\
\hline
\end{tabular}

جدول ז- نتايج مقايسٔ خرده مقياسهاى سازكارى زناشويى دو كروه آزمايش و كنترل با استفاده از آزمون من -ويتنى در مرحلة پيشآزمون.

\begin{tabular}{|c|c|c|c|c|c|c|c|}
\hline سطح معنى ارى & $\mathrm{Z}$ & من -ويتنى & جمع نمرات & ميانكين نمرات & تعداد & تروه مورد بررسى & خرده مقياس \\
\hline \multirow[b]{2}{*}{.199} & \multirow[b]{2}{*}{$-\cdot|f|$} & \multirow[b]{2}{*}{40} & Ifr & $11 / 94$ & ir & آزمايش & \multirow[b]{2}{*}{ رضايت زناشويى } \\
\hline & & & $I D V$ & $|r| \cdot 1$ & ir & كنترل & \\
\hline \multirow{2}{*}{. 194} & \multirow{2}{*}{.$- / 49$} & \multirow{2}{*}{$4 \pi / 0$} & $|f| / \phi$ & $11 / 29$ & ir & آزمايش & \multirow{2}{*}{ عمبستكَى دو نفرى } \\
\hline & & & $\mid Q N / Q$ & $|r / Y|$ & ir & كنترل & \\
\hline \multirow{2}{*}{$\cdot / V \Lambda$} & \multirow{2}{*}{$-\cdot / r \Lambda$} & \multirow{2}{*}{$91 / 9$} & $\mid f N / D$ & $\mid r / r \Lambda$ & ir & آزمايش & \multirow{2}{*}{ توافق دو نفرى } \\
\hline & & & IYV/D & $11 / 09$ & ir & كنترل & \\
\hline \multirow{2}{*}{$\cdot / r V$} & \multirow{2}{*}{$\cdot / 9$} & \multirow{2}{*}{$01 / 0$} & $\mid Q N / D$ & $|r / r|$ & ir & آزمايش & \multirow{2}{*}{ ابراز محبت } \\
\hline & & & $11 \mathrm{~V} / 0$ & $1 \cdot 191$ & ir & كنترل & \\
\hline
\end{tabular}

جدول بـ- نتايج مقايسٔ خرده مقياسهاى سازكارى زناشويى دو كروه آزمايش و كنترل با استفاده از آزمون من -ويتنى در مرحلة يسآزمون.

\begin{tabular}{|c|c|c|c|c|c|c|c|}
\hline سطح معنى هارى & $\mathbf{Z}$ & من ويتنى & جمع نمرات & ميانكين نمرات & تعداد & كروه مورد بررسى & خرده مقياس \\
\hline \multirow[b]{2}{*}{$\cdot / \cdot 1$} & \multirow[b]{2}{*}{$-Y / V T$} & \multirow[b]{2}{*}{ ro } & $19 \mathrm{~V}$ & Ig/4T & ir & آزمايش & \multirow[b]{2}{*}{ رضايت زناشويى } \\
\hline & & & $1 \cdot r$ & $N / \Delta \Lambda$ & ir & كنترل & \\
\hline \multirow{2}{*}{$\cdot 1 \cdot \varphi^{c}$} & \multirow{2}{*}{$-r / \cdot 9$} & \multirow{2}{*}{ re } & 119 & $10 / 0$ & ir & آزمايش & \multirow{2}{*}{ همبستكى دو نفرى } \\
\hline & & & 114 & $9 / \Delta$ & ir & كنترل & \\
\hline \multirow{2}{*}{$\cdot / \cdot 1$} & \multirow{2}{*}{$-r / V \Lambda$} & \multirow{2}{*}{ ry } & 191 & $19 / 0$ & ir & آزمايش & \multirow{2}{*}{ توافق دو نفرى } \\
\hline & & & $1 \cdot r$ & $N / \Delta$ & ir & كنترل & \\
\hline \multirow{2}{*}{$\cdot / \cdot r$} & \multirow{2}{*}{$-r / I V$} & \multirow{2}{*}{$1 V / 0$} & $r \cdot \varphi / \Delta$ & $\mid \mathrm{V} / \cdot \mathrm{F}^{\mathrm{c}}$ & ir & آزمايش & \multirow{2}{*}{ ابراز محبت } \\
\hline & & & $9 \Delta / \Delta$ & $V / 99$ & ir & كنترل & \\
\hline
\end{tabular}




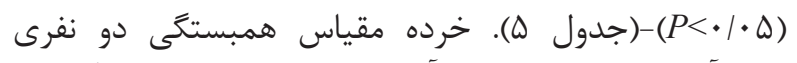

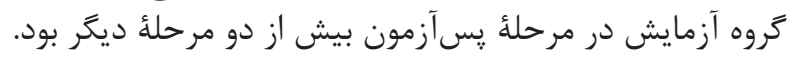

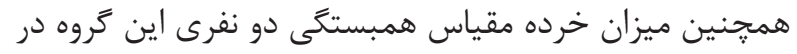

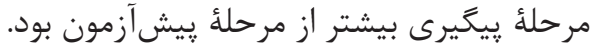

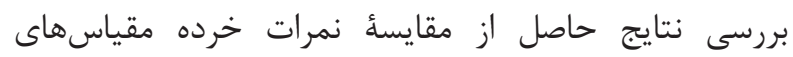

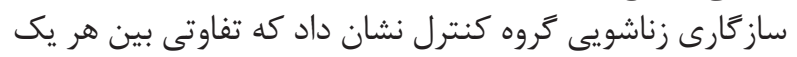

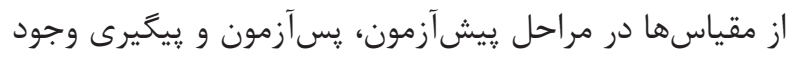

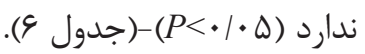

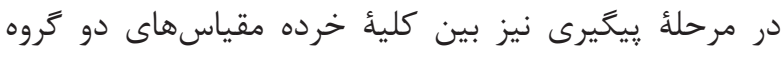

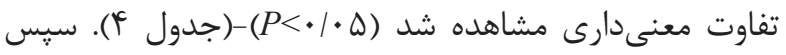

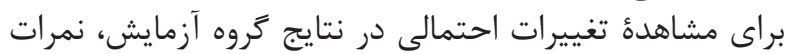

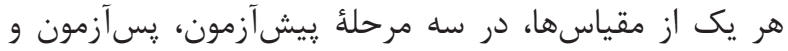

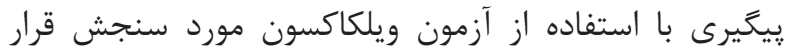

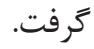
نمرات خرده مقياسهاى سازكارى زناشويى گروه آزمايش در

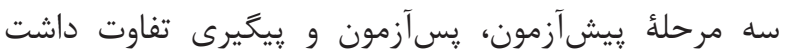

جدول F- نتايج مقايسٔ خرده مقياسهاى ساز كارى زناشويى دو كروه آزمايش و كنترل با استفاده از آزمون من -ويتنى در مرحلة بِيَيرى.

\begin{tabular}{|c|c|c|c|c|c|c|c|}
\hline سطح معنى دارى & $\mathrm{Z}$ & من كويتنى & جمع نمرات & ميانكين نمرات & ت تعداد & كروه مورد بررسى & خرده مقياس \\
\hline \multirow{2}{*}{$\cdot 1 \cdot 1$} & \multirow{2}{*}{$-T / 09$} & \multirow{2}{*}{ TF } & 119 & $10 / 0$ & ir & آزمايش & \multirow{2}{*}{ رضايت زناشويى } \\
\hline & & & 9. & $N / \Lambda$ & ir & كنترل & \\
\hline \multirow{2}{*}{$\cdot / \cdot r$} & \multirow{2}{*}{$-T / \cdot G$} & \multirow{2}{*}{$r 9 / 0$} & $1 \wedge \omega / 0$ & $10 / 49$ & ir & آزمايش & \multirow{2}{*}{ همبستكى دو نفرى } \\
\hline & & & $\| \mathrm{F} / \mathrm{D}$ & $9 / \Delta T^{T}$ & ir & كنترل & \\
\hline \multirow{2}{*}{$\cdot / \cdot 1$} & \multirow{2}{*}{$-T / V T$} & \multirow{2}{*}{ rt } & $1 M 1$ & $10 / 9 \mathrm{~V}$ & ir & آزمايش & \multirow{2}{*}{ توافق دو نفرى } \\
\hline & & & $M$ & $\Lambda$ & ir & كنترل & \\
\hline \multirow{2}{*}{$\cdot / \cdot r$} & \multirow{2}{*}{$-Y / 1$} & \multirow{2}{*}{$r 9 / 0$} & $11 \mathrm{D} / \mathrm{D}$ & $10 / 48$ & ir & آزمايش & \multirow{2}{*}{ ابراز محبت } \\
\hline & & & $11 \% / 0$ & $9 / \Delta T^{F}$ & ir & كنترل & \\
\hline
\end{tabular}

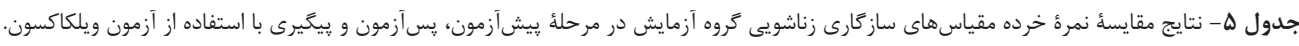

\begin{tabular}{|c|c|c|c|c|}
\hline سطح معنى & $\mathbf{Z}$ & تعداد ياسخدهندكان & مرحله & خرده مقياس \\
\hline$\cdot / \cdot r$ & $-H / \cdot \varphi$ & it & پيشآزمون - ֶِآزمون & \\
\hline$\cdot / \cdot f$ & $-r / \wedge \Delta$ & ir & ييشآزمون -يِيَيرى & رضايت زناشويى \\
\hline$\cdot / \cdot 1$ & $-\Gamma / \Delta T$ & it & يسآزمون -ييكيرى & \\
\hline$\cdot / \cdot 1$ & $-r / \Lambda \Delta$ & it & ييشآزمون -يسآزمون & \\
\hline$\cdot / \cdot I V$ & $-T / T V G$ & it & يبشآزمون -ييكيرى & همبستـى دو نفرى \\
\hline$\cdot / \cdot 11$ & $-r / T V \Delta$ & it & گسآزمون -يیخيرى & \\
\hline$\cdot / \cdot r$ & $-r / 9 \Lambda$ & it & ييشآزمون -يسآزمون & \\
\hline$\cdot 1 \cdot 4 q$ & $-T / 1 \Lambda$ & it & پيشآزمون - پييحيرى & توافق دو نفرى \\
\hline$\cdot / \cdot r$ & $-r / \cdot V$ & ir & يسآزمون -يیخيرى & \\
\hline$\cdot / \cdot r$ & $-r / \cdot V$ & it & ييشآزمون -يسآزمون & \\
\hline$\cdot / \cdot r$ & $-r / \cdot \Lambda$ & it & پيشآزمون -يِيَيرى & ابراز محبت \\
\hline $2 \cdot 1 \cdot 11$ & $-r / \Delta r$ & ir & يسآزمون -يِيَيرى & \\
\hline
\end{tabular}




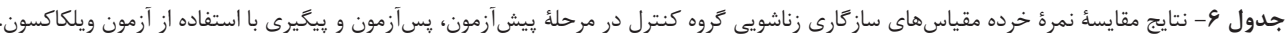

\begin{tabular}{|c|c|c|c|c|}
\hline سطح معنى دارى & $\mathbf{Z}$ & تعداد ياسخدهندًان & مرحله & خرده مقياس \\
\hline$\cdot|f|$ & $-\cdot / \Lambda r$ & ir & پيش آزمون - پيس آزمون & \\
\hline$\cdot / 19$ & $-1 / 19$ & IT & پيشآزمون -يیگيرى & رضايت زناشويى \\
\hline$\cdot / \mu_{1}$ & $-1 / \cdot r$ & IT & پسآزمون -يیخيرى & \\
\hline$\cdot|V|$ & $-\cdot / 09$ & IT & پيش آزمون - پِسآزمون & \\
\hline$\cdot / 11$ & $-1 / \Gamma$ & IT & پيش آزمون - پيخيرى & همبستـحى دو نفرى \\
\hline$\cdot / 4$ & $-\cdot / \wedge \Delta$ & IT & يسآزمون -بيكيرى & \\
\hline$\cdot / r \Lambda$ & $-1 / 14$ & it & پيش آزمون -یسآزمون & \\
\hline$\cdot / \Delta V$ & $-\cdot|\Delta|$ & IT & 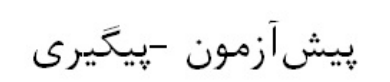 & توافق دو نفرى \\
\hline$\cdot /$ rV & $-\cdot / 91$ & ir & پسآزمون -ِيكيرى & \\
\hline$\cdot / 4$ & $-1 / T \Delta$ & it & ״يش آزمون - پيسآزمون & \\
\hline$\cdot /$ Mt & $-\cdot / \cdot 1$ & it & 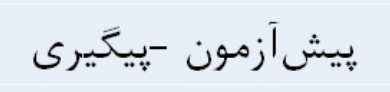 & ابراز محبت \\
\hline$\cdot / T \varphi$ & $-1 / 1 V$ & it & يسآزمون -ييكيرى & \\
\hline
\end{tabular}

رضايت زناشويى، همزمان سازكارى زناشويى نيز مى إنواند تغيير نموده و افزايش يابد (1) - (1).

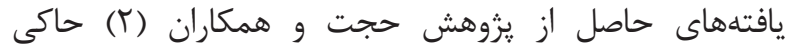

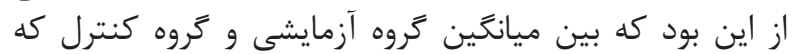

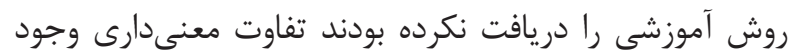

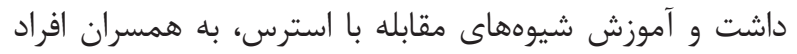

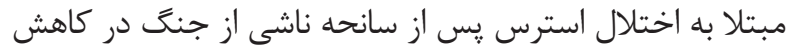

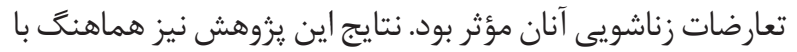

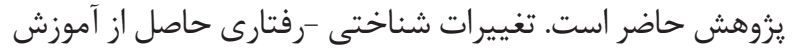

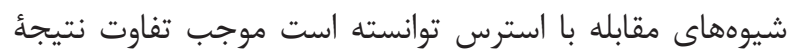

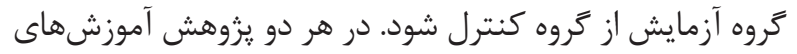

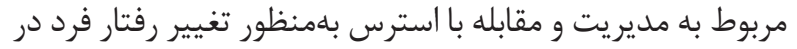

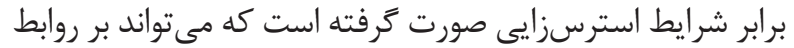

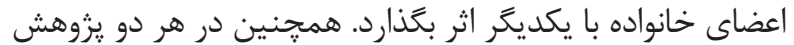

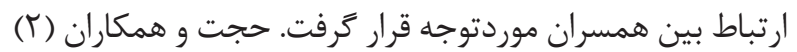

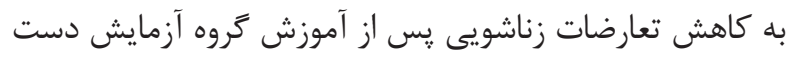

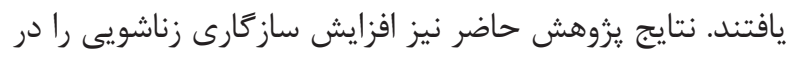
كروه آزمايش (يس از آموزش) نشان داضي

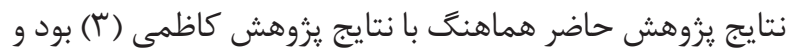

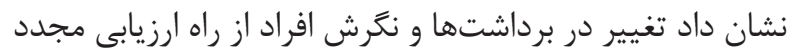

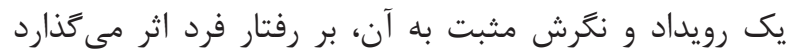

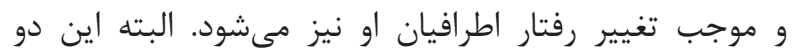

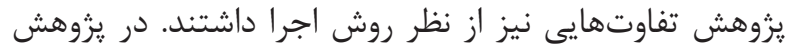

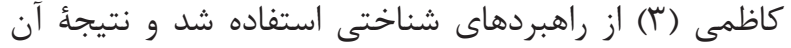

بحث و نتيجهلَيرى

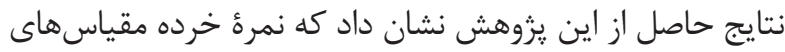

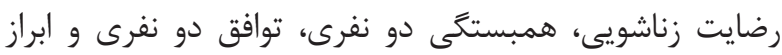

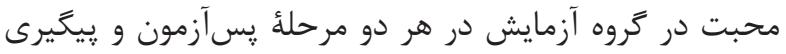

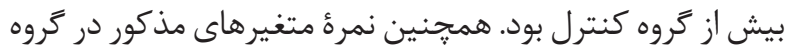

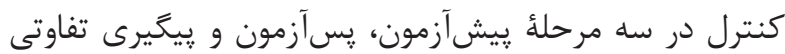

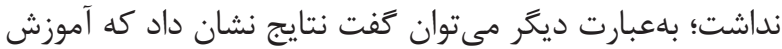

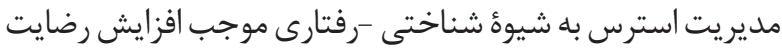

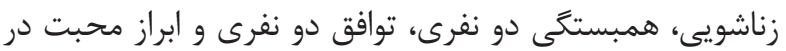

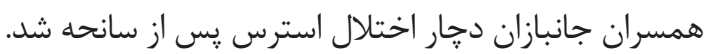

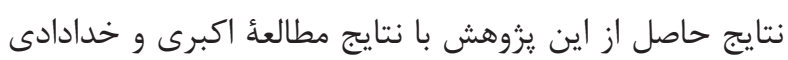

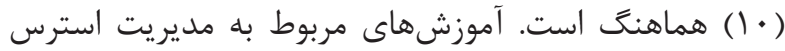

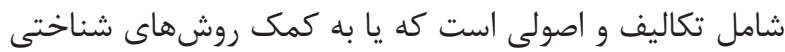

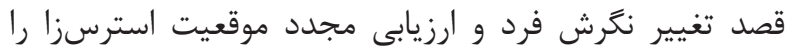

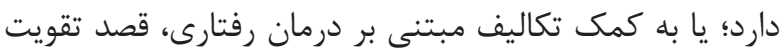

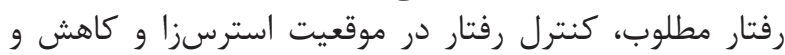

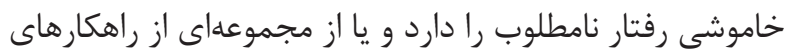

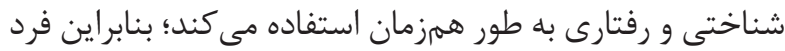

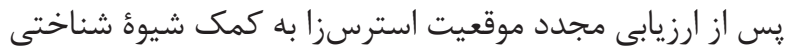

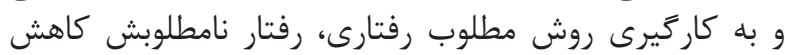

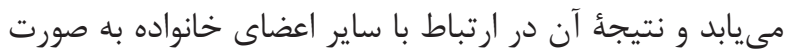

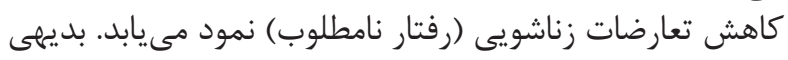

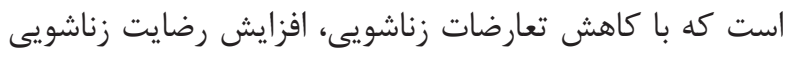

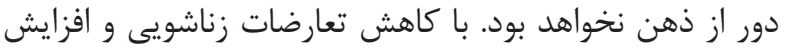


ممكن است به انتظارات منفى درباره تعارضهاى آينده منجر

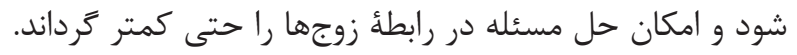

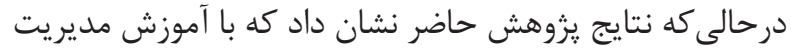

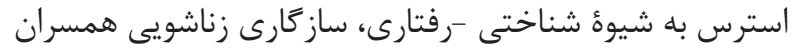

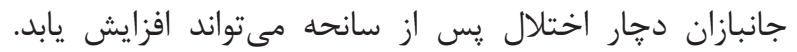

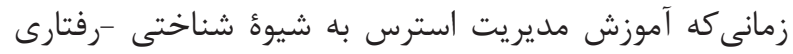

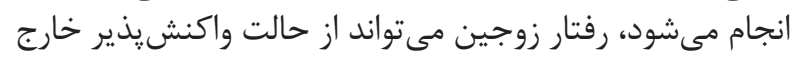

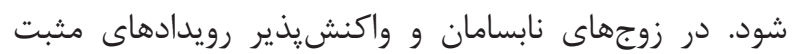

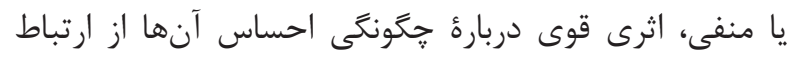

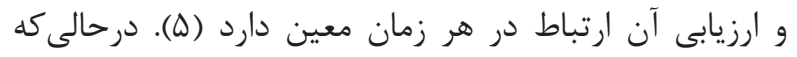

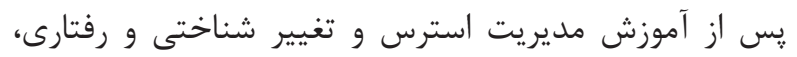

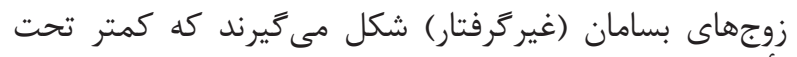
تأثير تغيير يذيرى لحظه به لحزئ لحظه هستند.

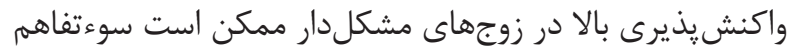

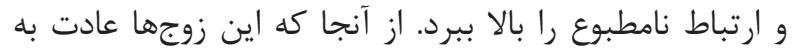

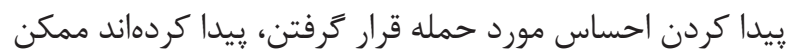

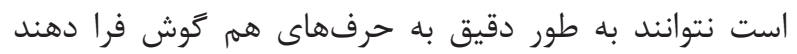

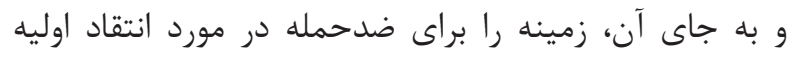

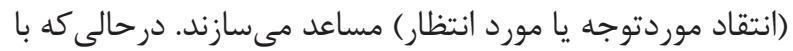

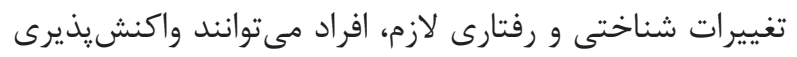

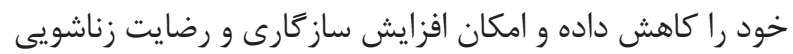

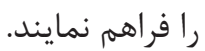

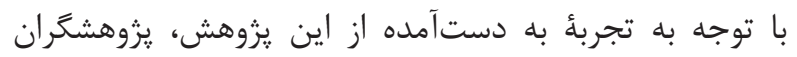

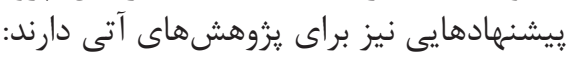

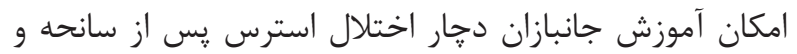

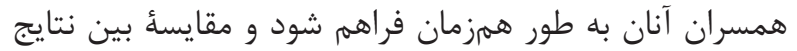

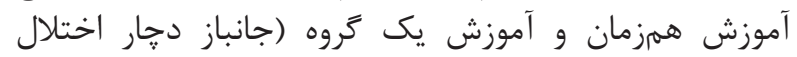

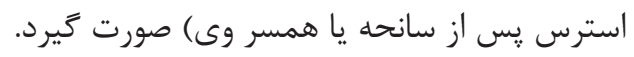

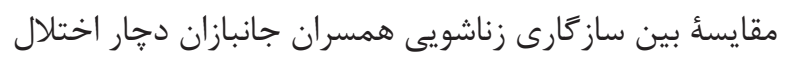

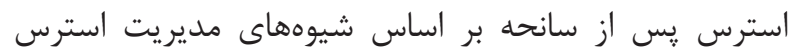

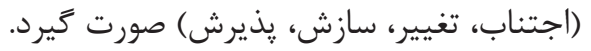

1. Ahmadi Zadeh M, Ahmadi Kh, Anisi J. Problemsolving therapy and a combination of face on consistency war veterans with post-traumatic stress disorder. Medical Logistics. 2012; 3: 178-88.

2. Hojat SK, Talebi M, Shakeri M, Zamiri Nejad S. Effectiveness of education on marital conflict couples coping with stress, post-traumatic stress disorder caused by war. J North Khorasan Univ Med Sci. 2012; 4: 185-90.

3. Kazemi A. Knowledge-based cognitive training effectiveness in reducing Brzhn secondary traumatic stress disorder and psychological problems of spouses of individuals with posttraumatic stress disorder. Journal of Thought and Behavior. 2012; 23: 31-42.

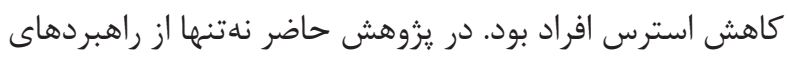

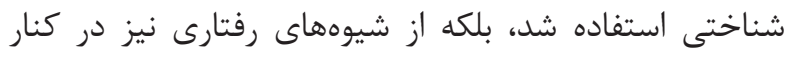

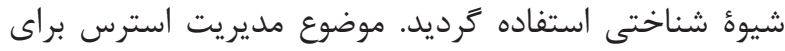

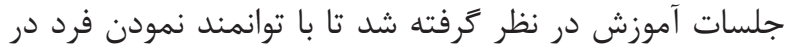

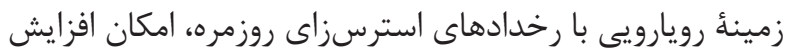

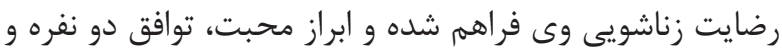
همبستكى زوجين افزايش يابد.

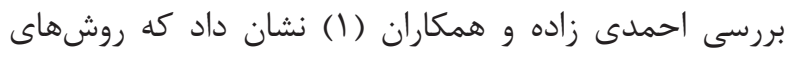

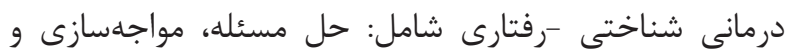

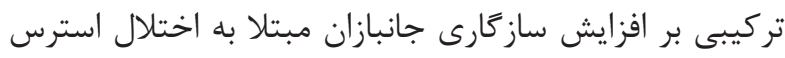

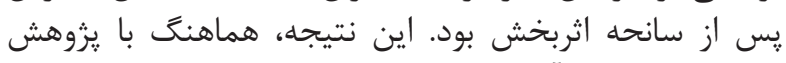

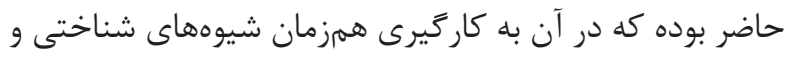

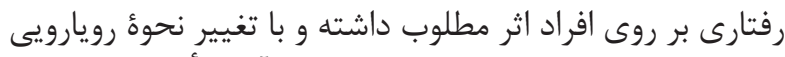

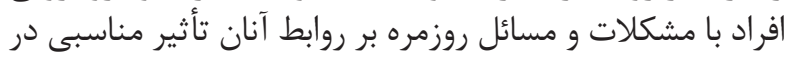
راستاى افزايش ساز گارى داشته است.

به اين ترتيب همانطور كه يزوهشهاى ييشين نيز نشان

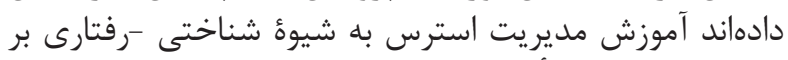

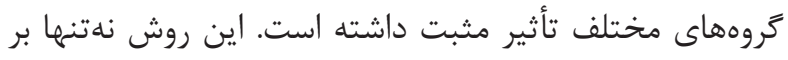

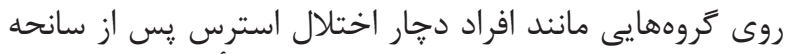

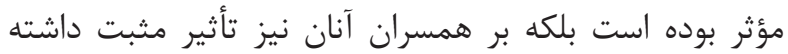

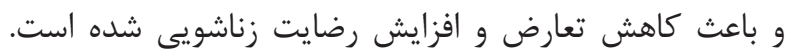

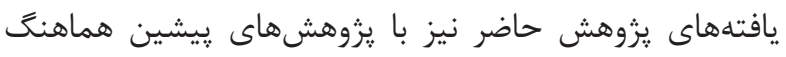

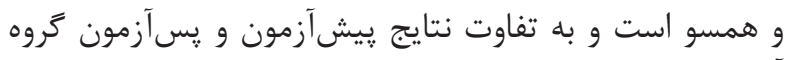

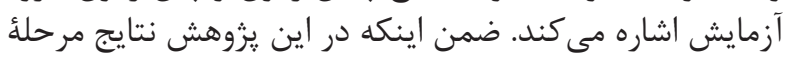

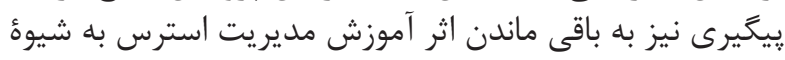

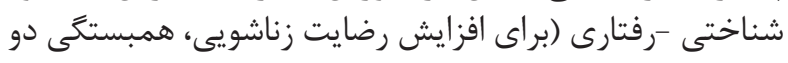

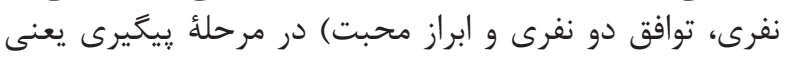

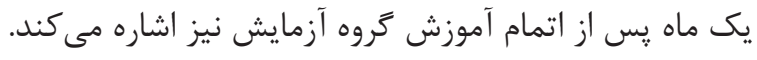

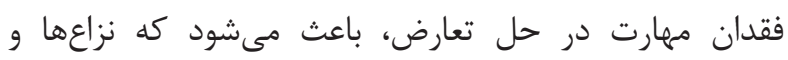

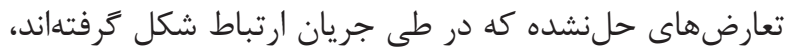

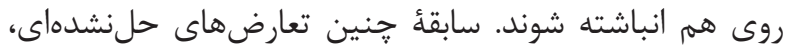

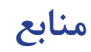

4. Sadock BJ, Sadock VA. Kaplan and Sadock's pocket handbook of clinical psychiatry. $5^{\text {th }}$ ed. Philadelphia: LWW. 2010; p. 205.

5. Jacobson NS, Follette WC, Mc Donald DW. Reactivity to positive and negative behavior in distressed and nondistressed married couples. J Consult Clin Psychol. 1982; 50: 706-14.

6. Noar SM, Zimmerman RS. Health behavior theory and cumulative knowledge regarding health behaviors: are we moving in the right direction? Health Educ Res, 2005; 20(3): 275-90.

7. Hawton K, Salkovskis PM, Kirk J, Clark DM. 


\section{0}

Cognitive behaviour therapy for psychiatric problems: a practical guide.1st ed. Oxford University Press. 1989; p. 347.

8. Lopez C, Antoni M, Penedo F, Weiss D, Cruess S, Segotas M, et al. A pilot study of cognitive behavioral stress management effects on stress, quality of life, and symptoms in persons with chronic fatigue syndrome. J Psychosom Res. 2011; 70: 328-34.

9. Barrera TL, Mott JM, Hofstein RF, Teng EJ. A meta-analytic review of exposure in group cognitive behavioral therapy for posttraumatic stress disorder. Clin Psychol Rev. 2013; 33(1): 24-32.

10. Akbari B, Khodadadi N. The effect of stress inoculation training on marital satisfaction and marital conflicts in spouses' with post-traumatic stress disorder. SJKU. 2013, 18(1): 94-103.

11. Smith CJ. Stress competence. Stress management: A comprehensive handbook of techniques and strategies. $1^{\text {st }}$ ed. New York: Springer Publishing Company. 2002; p. 15.

12. Sanai B. Measurement scales, marriage and family. $1^{\text {st }}$ ed. Tehran: Beasat Publication. 2001:73.

13. Mechanic D. Stress, illness and illness behavior. J Human Stress. 1976; 2(2): 2-6.

14. Critchley K. The nature of stress. Critchley K. Stress management, skills training course. $1^{\text {st }}$ ed. UK: Universe of learning Ltd. 2010; p. 31.

15. Lazarus RS, Folkman S. Cognitive theories of stress and the issue of circularity. Lazarus RS. Folkman S. Dynamics of stress. $1^{\text {st }}$ ed. New York: Springer; 1986; p. 63.

16. Fournier G, Jeanrie C. Locuse of control: back to basics. Lopez SJ, Snyder CR. Positive psychological assessment: A handbook of models and measures. $1^{\text {st }}$ ed. Washington: APA. 2003; p141. 